\title{
Avaliação in vivo do efeito hipocolesterolêmico e toxicológico preliminar do extrato bruto hidroalcoólico e decocção da Vitex megapotamica (Spreng) Moldenke (V. montevidensis Cham.)
}

\author{
Anna Paula Brandt,* Luís Flávio Souza de Oliveira, Franciele Bortoluzi Fernandes, \\ Janaina Alba
}

\author{
Curso de Farmácia, Universidade Comunitária Regional de Chapecó, Avenida Senador Atílio Fontana, 591-E, \\ Bairro Efapi, Caixa Postal 747, 89809-000 Chapecó-SC, Brasil
}

\begin{abstract}
RESUMO: As doenças cardiovasculares (DC) estão, de modo geral, associadas a elevados níveis séricos de lipídeos, atingindo homens e mulheres, sem distinção de idade. Entre as propriedades atribuídas pela medicina popular à Vitex megapotamica (Spreng) Moldenke (V. montevidensis Cham) - Tarumã estão a de reduzir os níveis séricos de colesterol e triglicerídeo. O principal objetivo do presente estudo foi avaliar o potencial hipocolesterolêmico e hipolipidêmico da $V$. megapotamica, bem como fazer um estudo toxicológico preliminar. Para tanto, foi realizada indução hiperlipidêmica usando um modelo que preconiza o emprego de propiltiuracil 1,25 mg/300 $\mathrm{g}$ de peso e colesterol $200 \mathrm{mg} / \mathrm{kg}$ de peso, aplicados via oral em ratos machos pesando $300 \pm 10 \mathrm{~g}$. Foi administrado, por via oral, aos animais hiperlipidêmicos previamente induzidos $300 \mathrm{mg} / \mathrm{kg}$ de extrato hidroalcoólico das folhas de V. megapotamica ou $300 \mathrm{~mL}$ da decocção da casca da planta. Após o final de cada tratamento, o perfil lipídico foi ensaiado, bem como os níveis de glicose, quando relevante. Nossos resultados confirmaram o efeito hipolipidêmico do extrato hidroalcoólico e da decocção pela redução dos níveis séricos de colesterol e triacilglicerol nas concentrações, via e forma utilizadas. Além disso, foi possível verificar que não houve lesão cardíaca, hepática ou renal pelo extrato e decocção utilizados nas avaliações toxicológicas preliminares ensaiadas.
\end{abstract}

Unitermos: Vitex megapotamica, Lamiaceae, hipocolesterolemia, hipotrigliceridemia.

\begin{abstract}
Evaluation of prospective hypocholesterolemic effect and preliminary toxicology of crude extract and decoction from Vitex megapotamica (Spreng) Moldenke (V. montevidensis Cham.) in vivo". The cardiovascular diseases are, in general, associated with high levels of serum lipids which have high incidence in middle-age men and women. Among other properties characterized by popular medicine, the Vitex megapotamica (Spreng) Moldenke (V. montevidensis Cham) - Tarumã, decreases the serum cholesterol and triacylglycerol levels. The main proposition of the present study was to evaluate the hypocholesterolemic and hipolipidaemic potential of $V$. megapotamica and to analyze the preliminary toxicity. It was an induction hyperlipidaemic model using propiltiuracil $1.25 \mathrm{mg} / \mathrm{kg}$ weight and cholesterol $200 \mathrm{mg} /$ $\mathrm{kg}$ weight per oros in male rats, weigthing $300 \pm 10 \mathrm{~g}$. It was administred to the animals $300 \mathrm{mg} /$ $\mathrm{kg}$ of hydroalcoholic leaves extract of $V$. megapotamica or $300 \mathrm{~mL}$ of hull decoction per oros. After the end of each treatment, the lipid profile was essayed as well as glucose, when relevant. Our results confirmed the V. megapotamica extract and decoction hypolipidaemic effect by the decrease of cholesterol and triacylglycerides serum levels in concentration, via and preparation performed. Furthermore, the toxicological preliminary assays showed there was not extract and decoction damage induction in cardiac and hepatic tissues, as well as in kidney physiology by assays performed.
\end{abstract}

Keywords: Vitex megapotamica, Lamiaceae, hypocholesterolaemia, hypotriglyceridaemia.

\section{INTRODUÇÃO}

As doenças cardiovasculares têm ganhado especial atenção, principalmente pela morbimortalidade demonstrada nos últimos anos nas sociedades industrializadas, onde se destaca a aterosclerose, responsável, no Brasil, por 32,6\% dos óbitos por doenças do aparelho circulatório (Santos \& Maranhão,
1998; Romaldini et al., 2004), como infarto agudo do miocárdio, angina, acidente vascular cerebral, entre outros (Serrano Junior et al., 2003).

Por outro lado, as plantas medicinais são, há muito tempo, utilizadas pela população com fins terapêuticos (Niero, 2003; Yamada, 1998; Barbosa-Filho et al., 2007; Cardoso-Lopes et al., 2008; Quintans-Júnior et al., 2008). De fato, sabe-se que dos 250 medicamentos 
considerados como básicos pela Organização Mundial da Saúde, 11\% são exclusivamente extraídos de plantas medicinais, e um número expressivo de fármacos semisintéticos e sintéticos também é obtido a partir de estruturas químicas de plantas (Niero, 2003).

Dentro deste contexto, a medicina popular aponta para a Vitex megapotamica (Tarumã) como uma planta dotada de propriedades terapêuticas, tais como anti-inflamatória, diurética, depurativa do sangue (hipocolesterolêmica), em casos de reumatismos e afecções cutâneas, distúrbios pulmonares, diminuição de peso corporal, dentre outros (Reyes AEL, 2003; Alice CB, 1995). De fato, seus constituintes farmacognósticos acenam para várias possibilidades terapêuticas. Contudo, se carece de estudos que comprovem tais efeitos. Sendo assim, este estudo teve como foco observar o efeito da decocção e do extrato bruto padronizado das folhas do Tarumã (Vitex megapotamica) sobre o perfil lipídico in vivo, já que sua etnofarmacobotânica a apresenta, dentre outras propriedades, anteriormente supracitadas, como capaz de produzir efeito hipolipemiante

\section{MATERIAL E MÉTODOS}

\section{Material botânico}

Os materiais vegetais utilizados foram as folhas e as cascas da Vitex megapotamica (Spreng) Moldenke (V. montevidensis Cham), conhecida popularmente como Tarumã. As amostras da planta foram coletada no mês de maio, entre os horários 10:00 e 11:00 da manhã, no Município de Seara, na localidade de São Rafael. Posteriormente, a partir das amostras da planta coletadas, foi confeccionada exsicata e enviada à Universidade Federal de Santa Maria para devida identificação botânica. O restante da amostra coletada foi utilizado para preparação do extrato bruto e da decocção.

\section{Secagem e preparação do extrato bruto e decocção}

As folhas e cascas da planta V. megapotamica foram secas a temperatura ambiente e abrigadas da incidência de luz direta sobre os farmacógenos para, em seguida, se obter o extrato bruto da folhas por turbólise, utilizando sistema etanol/água na proporção de 90:10 $(\mathrm{v} / \mathrm{v})$, com proporção entre droga vegetal e solvente de 1:4 (p/v). Após a filtração, o extrato foi depositado em rota-evaporador por cerca de 2 horas, a $25 \mathrm{rpm}, 40$ ${ }^{\circ} \mathrm{C}$, obtendo-se no final do processo $250 \mathrm{~mL}$ do mesmo, sendo esse volume fracionado em cápsulas de porcelana e secos por fonte térmica $\left(37^{\circ} \mathrm{C}\right)$. Em seguida, o extrato seco foi pesado e acondicionado a $-20{ }^{\circ} \mathrm{C}$ em frascos hermeticamente fechados para futura diluição e aplicação in vivo.

Já as cascas da $V$. megapotamica foram submetidas ao método extrativo da decocção com água destilada, tendo a proporção de casca/solvente de
1:100 (p/v), com base no uso popular, obtendo-se um volume total de $900 \mathrm{~mL}$, sendo este acondicionado a $4{ }^{\circ} \mathrm{C}$ em frasco âmbar limpo, seco e desengordurado e hermeticamente fechado.

\section{Análise fitoquímica preliminar}

A análise fitoquímica preliminar foi realizada segundo literatura especializada (Harbone, 1984; Bertucci et al., 2008), e observando a metodologia individual para cada reação conforme preconiza por Simões et al. (2000) para verificar a possível presença de grupos químicos do metabolismo secundário na droga vegetal.

\section{Controle de qualidade}

Para realizar o controle de qualidade foram observados parâmetros preconizados pela Farmacopéia Brasileira, sendo então verificada a perda por dessecação, a determinação de cinzas totais e o teor extrativo e resíduo seco (Farmacopéia Brasileira, 1988).

\section{Avaliação do efeito hipocolesterolêmico in vivo}

Para avaliar o efeito hipocolesterolêmico do extrato bruto das folhas e decocção das cascas da planta Vitex megapotamica, foram utilizados ratos albinos Wistar (Rattus norvegicus), machos, pesando $100 \pm 30 \mathrm{~g}$ provenientes do Instituto Tecnológico do Paraná (TECPAR). Os animais foram recebidos no Biotério da UNOCHAPECO, pesados e distribuídos randomicamente em grupos de 5 indivíduos por gaiola, mantidos a $24 \pm 2{ }^{\circ} \mathrm{C}$, com ciclo claro/escuro de 12 horas, passando por um período de adaptação de 7 dias, recebendo ração comercial padronizada e água $a d$ libitum.

A metodologia utilizada para indução hiperlipemiante foi preconizada por Fillios et al. (1956), Lustalot et al. (1961), com modificações (Oliveira, 2001). Inicialmente, ao Grupo I (controle), foi administrado via oral (v.o.) $0,4 \mathrm{~mL}$ de salina, durante o período experimental. Ao Grupo II (controle induzido), foi realizado pré-tratamento, onde se administrou 0,3 $\mathrm{mL}$ (V.O.) de propiltiuracil 1,25 mg, por 13 dias. Após este período, o grupo recebeu $0,4 \mathrm{~mL}$ (V.O.) de solução de colesterol $200 \mathrm{mg} / \mathrm{kg}$ de peso por 7 dias. Os grupos III e IV também receberam esse pré-tratamento, além do tratamento com extrato ou decoto, que perdurou 7 dias. Ao grupo III (induzido-tratado com extrato), foi administrado 0,3 mL (V.O.) de extrato bruto das folhas, na concentração de $300 \mathrm{mg} / \mathrm{kg}$ (Oliveira, 2001). Ao grupo IV (induzido-tratado com decocção) foi deixado à disposição dos animais $300 \mathrm{~mL}$ do decocto, sendo trocado diariamente.

Terminado o tratamento, os animais foram submetidos a jejum de 12 horas, seguindo-se coleta de 


\section{Concentrações Séricas de Colesterol}

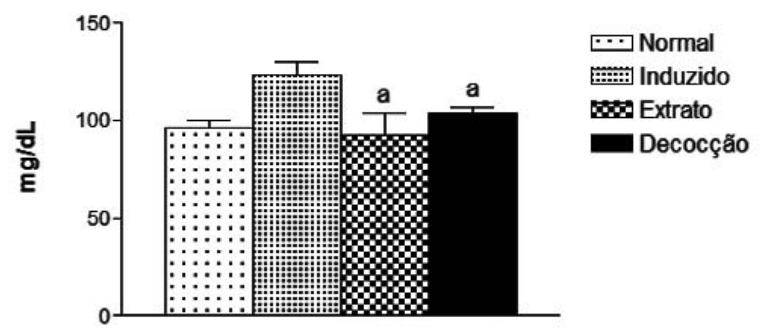

Figura 1. Concentrações séricas de colesterol. Os valores dos dados obtidos estão expressos em média, \pm SEM, aceitando um nível de significancia com $\mathrm{p}<0,05$ (ANOVA de uma via, complementada por Teste de Duncan); ${ }^{a}$ diferença estatisticamente significativa em relação ao grupo induzido.

amostras de sangue por punção retro-orbital, sob efeito anestésico de cetamina e xilazina, para realização das análises bioquímicas de glicose, colesterol total, HDLcolesterol, LDL-colesterol, triglicerídeos, proteínas totais, AST, ALT, creatinina, fosfatase alcalina e uréia. Para todas essas dosagens foram utilizados kits laboratoriais para análise BIOCLIN ${ }^{\circledR}$. Após o término das coletas de amostra biológica os animais forma eutanasiados em câmara de $\mathrm{CO}_{2}$.

Todo este trabalho foi apreciado e aprovado pelo comitê de ética da Universidade Comunitária Regional de Chapecó - UNOCHAPECÓ.

\section{RESULTADOS E DISCUSSÃO}

\section{Resultado dos testes de controle de qualidade}

Os testes de controle de qualidade revelaram que a droga vegetal apresentou uma perda por dessecação de $9 \%$, condizente ao preconizado em diferentes farmacopéias, onde os valores variam entre 8 e 14\%; o teor extrativo foi de $1,27 \%$; e para a determinação de cinzas totais obteve-se um resultado de $5 \%$.

\section{Concentrações Séricas de Triglicerídeos}

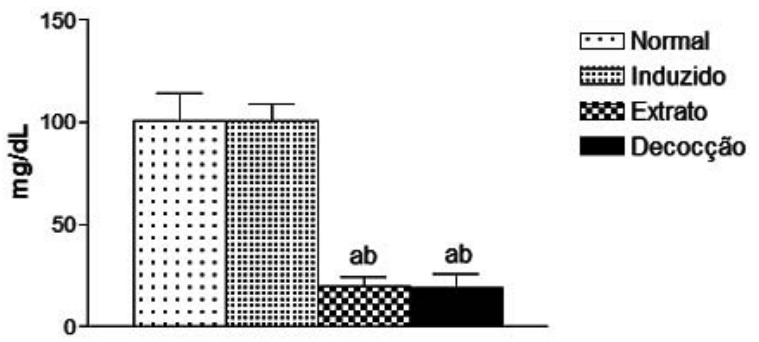

Figura 3. Concentrações séricas de triglicerídeos. Os valores dos dados obtidos estão expressos em média, \pm SEM, aceitando um nível de significancia com $\mathrm{p}<0,05$ (ANOVA de uma via, complementada por Teste de Duncan); ${ }^{\text {ab }}$ diferença estatisticamente significativa em relação aos grupos induzido e normal, respectivamente.

\section{Concentrações Séricas de HDL-Colesterol}

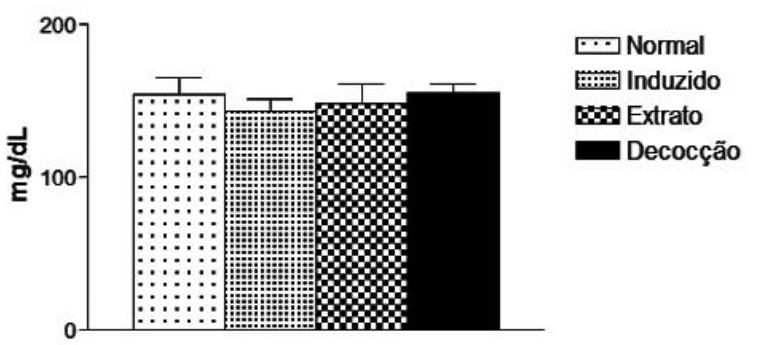

Figura 2. Concentrações séricas de HDL-colesterol. Os valores dos dados obtidos estão expressos em média, \pm SEM, aceitando um nível de significancia com $\mathrm{p}<0,05$ (ANOVA de uma via, complementada por Teste de Duncan).

\section{Resultado da análise fitoquímica preliminar}

A realização da análise fitoquímica preliminar das folhas da Vitex megapotamica (Tarumã) revelou a presença dos seguintes compostos: taninos, glicosídeos flavonônicos, polifenóis, alcalóides, óleos essenciais e saponinas.

É bem estabelecido que os flavonóides apresentam atividade antioxidante, colagoga, indutora microssomal hepática e inibidora das ciclooxigenases e lipoxigenase, sugerindo, respectivamente, a diminuição da oxidação do LDL-colesterol, aumento da excreção lipídica do organismo e diminuição de processos inflamatórios. Todos esses efeitos poderiam cooperar preventivamente à instalação da aterosclerose (Faludi et al., 2005; Oliveira et al., 2002).

Estudos relatam que a atividade farmacológica que os flavonóides possuem deriva de características específicas como complexação a íons metálicos, atividade antioxidante e seqüestradora de radicais livres e a capacidade de se complexar com moléculas como proteínas e polissacarídeos, podendo, assim, cooperar com a prevenção da instalação de doenças crônicodegenerativas de origem metabólica, onde é bem estabelecido o envolvimento de processos inflamatórios associados com geração de radicais livres (Monteiro et

\section{Concentrações Séricas de Glicose}

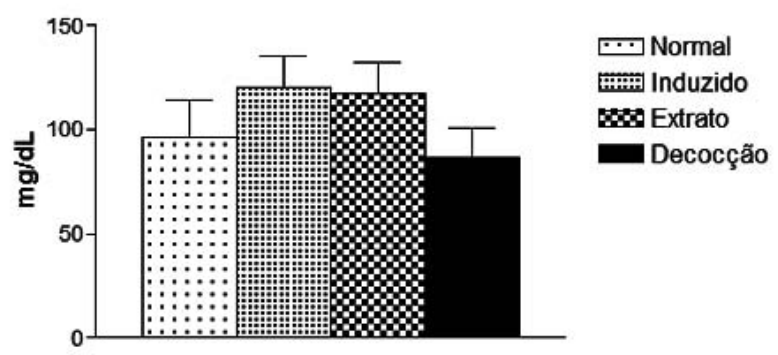

Figura 4. Concentrações séricas de glicose. Os valores dos dados obtidos estão expressos em média, \pm SEM, aceitando um nível de significancia com $\mathrm{p}<0,05$ (ANOVA de uma via, complementada por Teste de Duncan). 


\section{Concentraç̃es Séricas de Proteínas Totais}

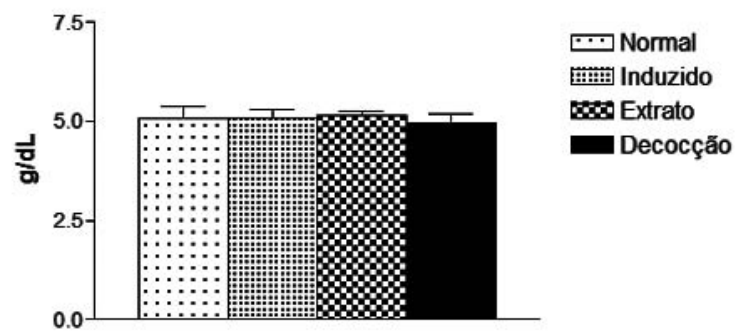

Figura 5. Concentrações séricas de proteínas totais. Os valores dos dados obtidos estão expressos em média, \pm SEM, aceitando um nível de significancia com $\mathrm{p}<0,05$ (ANOVA de uma via, complementada por Teste de Duncan).

al., 2005).

A presença de óleos essenciais no extrato bruto das folhas do Tarumã faz com que se reporte a possíveis propriedades farmacológicas dessa classe farmacognóstica, tais como carminativa, anitiinfamatória, secretolítica e cardiovascular, as quais poderiam contribuir para um efeito hipolipemiante e anti-aterogênico (Pinto et al., 2001).

As saponinas, segundo Simões et al., possuem a propriedade de se complexarem com o colesterol e, por isso, são utilizadas como hipocolesterolêmicas (Simões et al., 2000).

Dessa forma, é razoável pensar que os farmacógenos utilizados contêm grupos químicos relevantes que podem ter relações com efeitos hipolipemiantes.

\section{Resultado do teste in vivo do efeito hipolipidêmico da tarumã}

\section{Avaliação bioquímico-metabólica}

Após análise dos níveis séricos de colesterol total, se pode observar diferença estatística significativa entre o grupo induzido em relação aos grupos restante, todavia, não houve diferença entre os grupos normal,

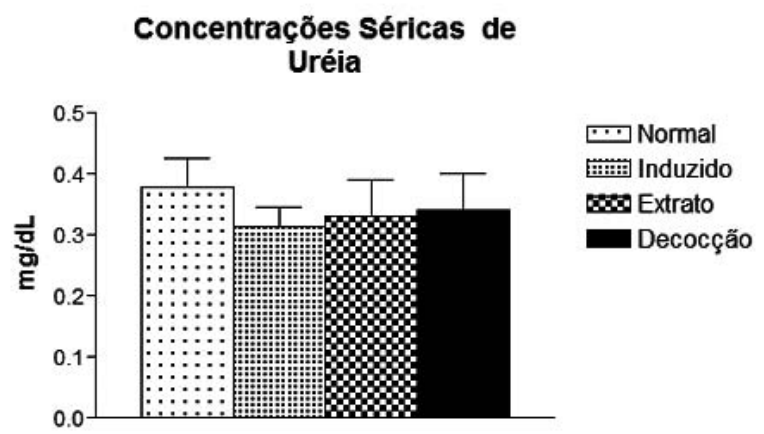

Figura 7. Concentrações séricas de uréia. Os valores dos dados obtidos estão expressos em média, \pm SEM, aceitando um nível de significancia com $\mathrm{p}<0,05$ (ANOVA de uma via, complementada por Teste de Duncan).

\section{Concentrações Séricas de creatinina}

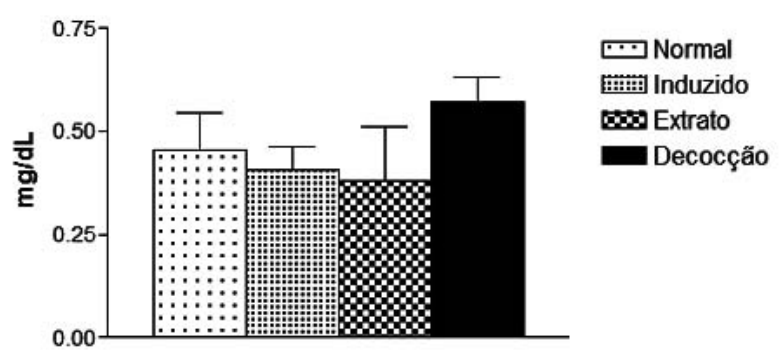

Figura 6. Concentrações séricas de creatinina. Os valores dos dados obtidos estão expressos em média, \pm SEM, aceitando um nível de significancia com $\mathrm{p}<0,05$ (ANOVA de uma via, complementada por Teste de Duncan).

extrato e decocção (Figura 1).

Os grupos tratados com extrato e decocção demonstraram ainda propriedade de recuperar, pelo menos em parte, os níveis de HDL-Colesterol, conforme é possível de se observar na Figura 2, havendo uma diferença estatística significativa entre o grupo normal e o restante dos grupos, bem como entre os grupos tratados e o grupo induzido. Todavia, entre os grupos tratados não houve diferença estatisticamente significativa.

Finalmente, encerrando as determinações diretamente relacionadas à constituição do perfil lipídico dos grupos, foram dosados os níveis de triglicerídeos que, por sua vez, se apresentaram surpreendentemente baixos e estatisticamente significativos nos grupos tratados com o extrato e com o decocto, apresentando uma redução de $80,63 \%$ quando comparado com os grupos normal e induzido (Figura 3). Contudo, não houve diferença estatística significativa entre os grupos normal e induzido, e os grupos tratados entre si.

Essa expressiva redução pode ser resultado da interferência do extrato bruto e decocto em diferentes vias metabólicas dos animais, como alterações na incorporação dos triglicerídeos exógenos aos

\section{Concentrações Séricas de Fosfatase Alcalina (FAL)}

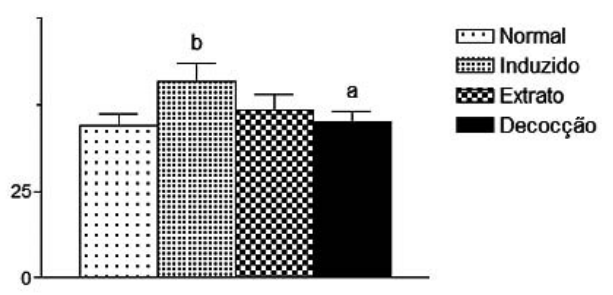

Figura 8. Concentrações séricas de fosfatase alcalina. Os valores dos dados obtidos estão expressos em média, \pm SEM, aceitando um nível de significancia com $\mathrm{p}<0,05$ (ANOVA de uma via, complementada por Teste de Duncan); ${ }^{a}$ diferença estatisticamente significativa comparada ao grupo induzido; b diferença estatisticamente significativa comparada ao grupo normal. 

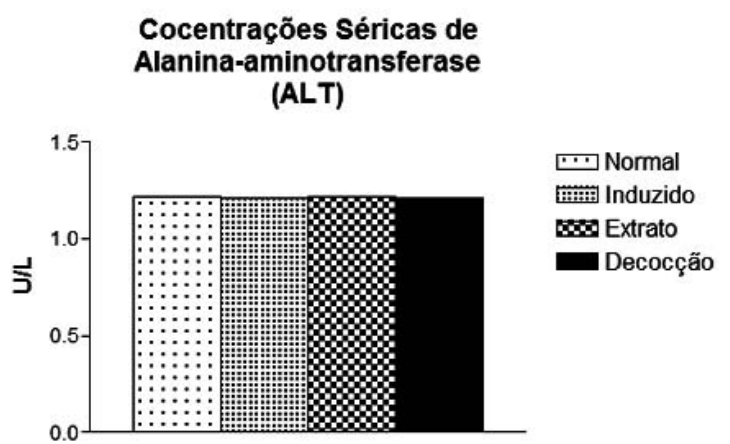

Figura 9. Concentrações séricas de alanina-aminotransferase (ALT) Os valores dos dados obtidos estão expressos em média, \pm SEM, aceitando um nível de significancia com $\mathrm{p}<0,05$ (ANOVA de uma via, complementada por Teste de Duncan).

quilomicra, uma possível indução da enzima lipase lipoprotéica (LPL), ou ainda a indução de receptores hepáticos. Todos esses eventos, isolados ou conjuntos, concorreriam para uma diminuição sérica dos valores deste lipídeo.

Como é possível perceber, as dosagens de colesterol total, HDL-colesterol e triglicerídeos concorrem harmonicamente para um efeito hipolipidêmico interessante das preparações utilizadas, o que vem corroborar com o emprego da planta na medicina popular como droga hipolipemiante.

A análise dos níveis de glicose e proteínas totais (Figuras 4 e 5) não demonstrou diferença estatisticamente significativa entre os grupos, o que sugere que a ação das preparações utilizadas não se dá ao nível de absorção intestinal, mas após esta etapa.

\section{Avaliação bioquímica toxicológica preliminar}

Para realizar uma análise toxicológica preliminar do extrato utilizado, bem como da decocção, foram estabelecidos os seguintes parâmetros bioquímicos: creatinina, uréia, fosfatase alcalina, alanina aminotransferase e aspartato aminotransferase.

Os resultados obtidos a partir da dosagem de creatinina e uréia demonstraram não haver diferença estatisticamente significativa entre os grupos, conforme é possível visualizar nas Figuras 6 e 7, respectivamente. Sendo assim, estes resultados parecem apontar para ausência de lesão renal pelas preparações e via utilizadas.

A avaliação da função hepática compreendeu as dosagens dos níveis séricos de fosfatase alcalina (FAL), alanina aminotransferase (ALA) e aspartato aminotransferase (AST) frente aos tratamentos realizados. As dosagens de FAL demonstraram uma diferença estatística significativa nos valores obtidos com o grupo normal em relação ao grupo induzido, com aumento de 22,55\% neste último. Além disso, houve redução de $20,65 \%$ no grupo induzido-tratado

\section{Concentrações Séricas de \\ Aspartato-aminotransferase (AST)}

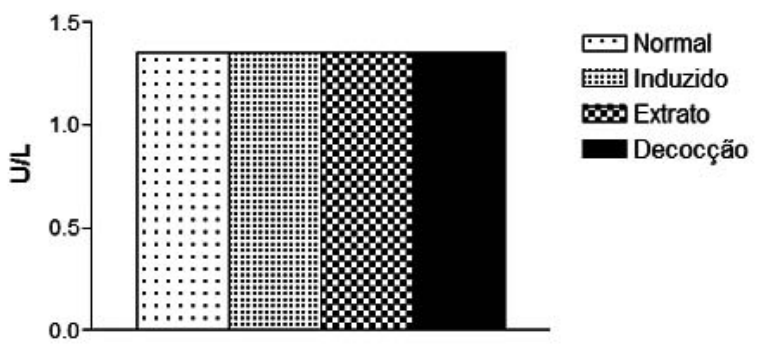

Figura 10. Concentrações séricas de aspartato-aminotransferase (AST) Os valores dos dados obtidos estão expressos em média, \pm SEM, aceitando um nível de significancia com $\mathrm{p}<0,05$ (ANOVA de uma via, complementada por Teste de Duncan).

com decocto, em relação ao grupo induzido, conforme Figura 8.

O interesse clínico na dosagem de FAL está diretamente relacionada à obstrução biliar (Henry, 1996) e, como pôde ser visualizado, o resultado obtido com o grupo induzido é sugestivo de que o excesso de colesterol não incorporado aos tecidos extra-hepáticos, poderia estar sendo depositado na vesícula biliar ou nos canais que a ligam ao intestino. Entretanto, o tratamento com o decocto demonstrou a recuperação da alteração hepática produzida pela administração de colesterol, sugerindo uma ação hepatoprotetora a partir desta preparação.

As transaminases AST e ALT estão amplamente distribuídas nos tecidos humanos, contudo é importante ressaltar que a ALT é uma enzima dotada de relativa especificidade hepática, se apresentando normal após infarto do miocárdio, mas alterada em lesão hepática oriunda de insuficiência hepática, bem como em casos de pancreatite (Henry, 1996).

Nas dosagens realizadas dessas enzimas, não houve diferença estatística significativa nos resultados obtidos, tanto de ALT quanto de AST, conforme observado nas Figuras 9 e 10, o que sugere não ter havido aparentemente prejuízo hepático com o uso das preparações testadas.

\section{CONCLUSÃO}

Dessa forma, é possível concluir que este estudo aponta para um efeito hipolipidêmico do extrato hidroalcoólico e da decocção pela redução dos níveis séricos de colesterol e triacilglicerol nas concentrações, via e forma utilizadas, o que, de certa forma, coopera para a validação da planta quanto ao seu uso na medicina popular. Além disso, foi possível verificar que não houve lesão cardíaca, hepática ou renal pelo extrato e decocção utilizados nas avaliações toxicológicas preliminares ensaiadas. 


\section{REFERÊNCIAS}

Alice CB 1995. Plantas medicinais de uso popular: atlas farmacognósticos. Canoas: Ulbra.

Barbosa-Filho JM, Nascimento-Júnior FA, Tomaz ACA, Athayde-Filho PF, Silva MS, Cunha EVL, Souza MFV, Batista LM, Diniz MFFM 2007. Natural products with antileprotic activity. Rev Bras Farmacogn 17: 141148.

Bertucci A, Haretche F, Olivaro C, Vázquez A, 2008. Prospección química del bosque de galería del río Uruguay. Rev Bras Farmacogn 18: 21-25.

Cardoso-Lopes EM, Carreira RC, Agripino DG, Torres LMB, Cordeiro I, Bolzani VS, Dietrich SMC, Young MCM 2008. Screening for antifungal, DNA-damaging and anticholinesterasic activities of Brazilian plants from the Atlantic Rainforest - Ilha do Cardoso State Park. Rev Bras Farmacogn 18 (Supl.): 655-660.

Faludi AA, Zatz HP, Araújo DB, Bertolami MC 2005. Como diagnosticar e tratar dislipidemias. Rev Bras de Med 5: 174-180.

Farmacopéia Brasileira 1988. São Paulo: Atheneu.

Harbone JB 1984. Phitochenical metods: a guine to moder tecniqus of plants analisys. New York: Chapman Nahall.

Henry JB 1996. Diagnósticos clínicos e tratamento por métodos laboratoriais. São Paulo: Manole.

Monteiro JM, Albuquerque UP, Araujo EL, Amorim ELC 2005. Taninos: uma abordagem da química à ecologia. Quim Nova 5: 892-896.

Niero R 2003. Aspectos químicos e biológicos de plantas medicinais e considerações sobre fitoterápicos. In Chechinel Filho V, Bresolin TMB. (org). Ciências químico-farmacêuticas: Contribuição ao desenvolvimento de novos fármacos e medicamentos. Itajaí: Univalli, p.150-215.

Oliveira LF 2001. Avaliação in vivo do efeito hipocolesterolêmico do extrato metanólico de Aleurites moluscana, xantoxilina e derivados. Florianópolis, 150p. Dissertação de Mestrado - Programa de PósGraduação em Farmácia, Universidade Federal de Santa Catarina.

Oliveira TT, Gomes SM, Nagem TJ, Costa NMB, Secom PR 2002. Efeito de diferentes doses de flavonóides em ratos hiperlipidêmicos. Rev Nutr 1: 45-51.

Pinto MM, Gonçalez E, Rossi MH, Felício JD, Medina CS, Fernandes MJB, Simoni IC 2001. Atividade do extrato aquoso de folhas de Polymnia sonchifolia no crescimento e produção de aflotoxinas B1 por Aspergillus flavus. Braz J Microbiol 2: 127-129.

Quintans-Júnior LJ, Almeida JRGS, Lima JT, Nunes XP, Siqueira JS, Oliveira LEG, Almeida RN, Athayde-Filho PF, Barbosa-Filho JM 2008. Plants with anticonvulsant properties - a review. Rev Bras Farmacogn 18 (Supl.): 798-819.

Reyes AEL 2003. Árvores Frutíferas Tarumã Mitex montevidensis Cham. Disponível em: http://www. esalq.usp.br/trilhas/fruti/fr01.php. Acessado em 13 de setembro.

Romaldini CC, Issler H, Cardoso AL, Diament J, Forti N 2004. Fatores de risco para aterosclerose em crianças e adolescentes com história familiar de doença arterial coronariana prematura. J Pediatria 2: 135-140.

Santos RD, Maranhão RC 1998. Comparação entre homens e mulheres hipercolesterolêmicos de alto risco de desenvolvimento de aterosclerose. Estudo dos fatores de risco e da resposta ao tratamento com pravastatina. Arq Bras Cardiol 6: 383-387.
Serrano Junior CV, Souza JÁ, Paiva MSMO 2003. Fatores desencadeantes da instabilização da placa aterosclerótica. Rev Soc Cardiol 4 :724-732.

Simões CMO, Schenkel EP, Gosmann G, Mello JCP, Mentz LA, Petrovick PR 2000. Farmacognosia: da planta ao medicamento. Florianópolis: UFSC.

Yamada CSB 1998. O crescente papel das plantas medicinais nos cuidados de saúde na Europa. Rev Racine 43: 1525. 